\title{
Is It Still Where I Expect It?—Users' Current Expectations of Interface Elements on the Most Frequent Types of Websites
}

\author{
Silvia Heinz ${ }^{1, *}$, Sebastian LinXen ${ }^{1,2}$, AleXandre N. Tuch ${ }^{1}$, Lars Fraßeck $^{1}$ \\ AND KLAUS OPWIS ${ }^{1}$ \\ ${ }^{1}$ Department of Psychology, Center for Cognitive Psychology and Methodology, University of Basel, \\ Missionsstrasse 62a, 4055 Basel, Switzerland \\ ${ }^{2}$ University of Applied Sciences and Arts Northwestern Switzerland School of Business, \\ Peter Merian-Strasse 86, 4002 Basel, Switzerland \\ ${ }^{*}$ Corresponding author: silvia.heinz@unibas.ch
}

\begin{abstract}
Knowing users' expectations about what they expect on a website and where they expect to find it is crucial for the success of a website. For the last decade, technological advances have entailed major changes in website design but the impact of these changes on users' mental representations of websites remains unclear. In an online study $(N=841)$, we asked users to sketch their prototypical version of an online shop, a news website and a company page, thereby indicating the interface elements they expect on the website and their expected location. We compared our results to those of a previous study to investigate changes in users' mental representations of websites over time. This comparison suggests that interface elements such as the logo, main content and navigation area are still expected in the same location although others have shifted to the rich footer area at the bottom of the website. In addition, new elements such as links to social networks have been incorporated into users' mental representations whereas other interface elements have disappeared. By providing updated consolidated blueprint models for all three website types, we help designers to create

expectation-based websites. Further implications for research and practitioners are discussed.
\end{abstract}

\section{RESEARCH HIGHLIGHTS}

- Measuring current expectations about the location of interface elements,

- Website layout: composition and expected location of interface elements,

- Gain insights into developments in users' expectations over time.

Keywords: expectations; website design; mental models; location of interface elements; user interface; differences over time

Editorial Board Member: Prof. Paul van Schaik

Received 22 June 2015; Revised 4 March 2016; Accepted 18 March 2016

\section{INTRODUCTION}

Online shopping and reading news online are, along with informational searches, frequent tasks that are performed on websites and therefore need to be able to be performed efficiently. According to recent statistics, after search engines
(74\%) and social networking sites $(64 \%)$, web portals $(55 \%)$, news websites (42\%), shopping and auction sites (35\% and $39 \%$, respectively) are among the website types users visit at least once a week (Statista, 2013). Knowing what kind of interface elements (e.g. main navigation, search area) users 
expect on a specific website type, as well as knowing their expected location, can support developers in designing userfriendly and efficient websites. Previous research has shown that users are quicker in finding an element of the interface (McCarthy et al., 2004; Roth et al., 2013) and have less trouble orienting themselves on a website when the sites are designed according to their expectations (Oulasvirta et al., 2005; Santa-Maria and Dyson, 2008). Users find it easier to access information if interface elements are where they expect (Baharum and Jaafar, 2013b) and tend to be more satisfied with the site (Shaikh and Lenz, 2006).

Due to the technological advances as well as changes in website design, a typical website nowadays looks different to a website from 5 years ago (Kienle and Distante, 2014; O'Reilly and Battelle, 2009; Trends in web technology, 2015). It remains unclear, however, if users' expectations and mental representation of websites have changed as well. Some studies have to a certain extent compared their results to previous studies (Albert et al., 2009; Shaikh and Lenz, 2006), but to the authors' best knowledge, no systematic longitudinal comparison of users' mental representations of websites has been conducted.

There are different approaches to examining users' expectations and mental representations of the layout of a website. Numerous studies have assessed and aggregated users' expectations of websites (Baharum and Jaafar, 2013a, 2013b, 2014; Bernard, 2001a, 2001b, 2003; Bernard and Sheshadri, 2004; Harinarayana et al., 2011; Linxen et al., 2014; Lynch and Horton, 2008; Rotht et al., 2010; Shaikht et al., 2006; Shaikh and Lenz, 2006). For instance, Bernard (2001a) asked participants to indicate on a grid where they expect different interface elements to be located and assessed the 'prototypical representations' of e-commerce websites. Roth et al. (2010) assessed users' expectations about the location of different interface elements by using an online sketching tool. Participants were able to sketch how they imagined typical websites and from the aggregated sketches the authors derived a prototypical mental representation of three different website types, namely online shops, news websites and company websites.

To investigate whether users' mental representations of different website types have changed over time, in the present study we used an online sketching application allowing participants to compose their prototypical websites by freely arranging interface elements and compared our results to users' mental representations of websites in the previous study by Roth et al. (2010). In doing so, we were able to study how changes in interface design (such as the introduction of the rich footer, a link collection to important website content at the bottom of a website) have affected users' mental representations of websites and, furthermore, illustrate which new elements have become central to users' perception of websites.

This study aimed to (i) assess which interface elements users expect to be present on three different types of websites; (ii) visualize users' mental prototypes of these three website types and (iii) identify and highlight changes in users' prototypical mental representations over time by comparing our results to a previous study, and link these changes to recent developments in website design. Furthermore, we aimed to highlight the robustness and the dynamics of users' mental representations of websites over time.

\section{THEORETICAL BACKGROUND AND RELATED WORK}

In the following section, we introduce the concept of expectations within the field of human-computer interaction (HCI), and how users' expectations can be captured. To explain the potential changes compared to results of previous studies, we further highlight some recent trends in website design.

\subsection{Why it is important to know users' expectations?}

Expectations are the unconscious predictions that human beings make constantly to model the world around them in order to predict and judge their environment (Jonassen and Henning, 1996; Norman, 1983). Expectations are helpful for anticipating events such as crossing the street and estimating the speed of an approaching car. Nowadays, based on their experience, Internet users expect that the reactions and feedback of a website will be unambiguous and that the design and interaction will adhere to certain customs, standards and guidelines. This is also reflected in one of the dialog principles of the ISO 9241110 standard (ISO 9241-11(E), 1998), which outlines the importance of an interface being in accordance with users' expectations. Accordingly, studies have shown that participants are able to solve more tasks and report a lower perceived mental workload when searching information on websites with prototypical versus non-prototypical arrangements of interface elements (Owens et al., 2014), or that users can find certain interface elements faster if a website is built according to their expectations (Auinger et al., 2011; Oulasvirta et al., 2005; Roth et al., 2013). Furthermore, Santa-Maria and Dyson (2008) showed that having a prototypical interface can ease the disorientation that users experience when using a system for the first time. In another study, participants were able to correctly categorize prototypical websites even when seeing them only for milliseconds, which suggests that users' mental representations of websites are accessible in an extremely fast manner and help to guide users' perception of websites (Owens, 2013). Websites that do not meet users' expectations, however, can lead to frustrating experiences (Cassidy and Hamilton, 2014; Nadkarni and Gupta, 2007; Palmer, 2002). As a consequence, users may just leave a website and never come back (Bhattacherjee, 2001; Cyr, 2014; Flavián et al., 2006). This, of course, can have a serious impact on the success of a website provider or, even worse, on the image of the corresponding company (Auinger et al., 2011; Soper and Mitra, 2013). 
In the literature, users' internal representations of websites are often referred to as 'mental models' (e.g. Bernard and Sheshadri, 2004; Qian et al., 2011; Roth et al., 2010). In cognitive psychologyc, 'mental models' are internal knowledge representations of an external reality (Gentner and Stevens, 1983; Johnson-Laird, 1983). Early work by Craik (1943) defines them as internal working models for external events, like a small-scale model of how the world works. They have predictive functions to make sense of our environment, are subject to change, and are often formed on the fly (Davidson et al., 1999). Mental models are dynamic (Craik, 1943; Johnson-Laird, 1983) and can change over time (Thatcher, 2008). Norman (1983) and Nielsen (1999) adopted the term 'mental model' in early HCI research to describe users' simplified internal representations or working models of how a computer system works (Jonassen and Henning, 1996). A mental representation of a website is understood to be an user's 'mental blueprint' of a website, including information such as the general structure of a website and the spatial location of its interface elements (Di Nocera et al., 2004; Owens, 2013; Rapp, 2005). Norman (1983) argued that to avoid usability problems designers should be aware of the users' mental representations of software tools when designing its interface.

\subsection{How to assess users' mental representations of websites}

Cassidy and Hamilton (2014) reported that since Bernard's (2001a, 2001b) first studies, several researchers have analyzed users' expectations of websites using different approaches. In the following section, we describe different methods of how to assess users' expectations.

Research often aggregated and displayed users' expectations in the form of visualizations within a predefined and superimposed grid on a blank website (e.g. Bernard, 2001a, 2001b; Shaikh and Lenz, 2006). Placing interface elements on paper or indicating their position within a grid seems a straightforward way of collecting information about users' mental representations of websites. For instance, Bernard (2001b) used a $7 \times 8$ grid representing a browser window where participants could place given interface elements. Several studies have applied this method with different grid sizes (Baharum and Jaafar, 2013a; Bernard, 2003; Harinarayana et al., 2011; Shaikh and Lenz, 2006; Suresh and Gopalakrishnan, 2012). This grid approach was also used in an online study where participants could indicate their 'prototypical representation' of online shops (Roth et al., 2010). Roth et al. (2010) used an online application where users could sketch their mental representations of different website types. In contrast to previous studies, where users often placed each interface element separately and unrelated to others, they used a holistic approach, where participants were asked to compose three types of websites such as an online shop, a news website and a company page using given interface elements as building blocks. All interface elements were presented at the same time, participants could choose which interface elements they wanted to place, and they could adapt the size of each interface element. The results were aggregated into consolidated 'blueprints' for each website type (Roth et al., 2010).

\subsection{Mental representations of different types of websites and interface elements}

Some studies on mental representations have only included one type of website such as either e-commerce, or library, or travel websites (Adkisson, 2002; Kim and Fesenmaier, 2008; Naughton and Agosto, 2012; Purwati, 2011; Vasantha and Harinarayana, 2011) whereas others have included and compared different types of websites (Cassidy and Hamilton, 2014; Roth et al., 2010). To categorize websites into different types and analyze them separately seems a sensible approach because previous studies indicate that users have different expectations regarding which interface elements can be found on different website types (Roth et al., 2010). With regard to the concrete interface elements used, Cassidy and Hamilton (2014) summarized that in previous studies on mental representations a total of 22 different elements had been investigated. These were generic elements such as logo, navigation and search but also website-type specific elements such as shopping cart.

\subsection{Changes in location expectations of interfaces element}

Expectations about our world and its internal representations can change (Holman, 2011; Shaikh and Lenz, 2006). Only a few studies have analyzed differences in users' mental representations over time. For instance, McCarthy et al. (2004) showed that if users were confronted with violations of their expectations they were able to quickly adapt to non-standard layouts in websites. Therefore interacting with an evolving system such as a website or any interactive system must provoke the user's old model to adapt to the new system (Neisser, 1976; Qian et al., 2011). Other studies about mental representations of websites have compared their results to previous studies to get an estimate of how these have changed over time. Shaikh and Lenz (2006) and Baharum and Jaafar (2013b) replicated the studies of Bernard (2001a, 2001b) and compared their results. Overall, they were able to show very few changes for several selected interface elements. These studies comparing results over time, however, used different approaches and different grid sizes than the former studies.

Overall, these comparisons to previous studies indicate a stable expected location for some of the elements such as logo, or the main content of a website, whereas they reported differences for other elements such as the main navigation and search. Due to the constant advances and changes in 
Internet technologies, it remains important to re-examine users' expectations about the positioning of interface elements (Baharum and Jaafar, 2013c).

\subsection{Change in web design}

In the following section, we discuss some technological developments and trends in web design that might have had an impact on which elements users expect on a website and where they expect to find them. These technological changes, together with the modified visual appearance of websites, may affect users' expectations (Baharum and Jaafar, 2013c). To increase product sales, different techniques are applied, such as using banner advertisement on websites, using wish lists or other persuasive selling strategies, or giving users the possibility to personalize the website (Gerrikagoitia et al., 2015). Adaptation of these strategies impacts the visual design of websites, as does the use and integration of social media and social networks. This could be observed for different types of websites such as library websites (Vasantha and Harinarayana, 2011), education and instructional design (Tess, 2013), travel and tourism (Xiang et al., 2014) or even search engines (Mlilo et al., 2011).

Some interface elements, such as links to social media, have been used by several websites and developed into de facto standards (Adkisson, 2002; Albert et al., 2009). Social media also influence how customers interact on e-commerce sites (Huang and Benyoucef, 2013). To determine whether these described technological and design changes have influenced users' mental representations of websites and to monitor their robustness, it is necessary to measure and capture users' expectations over time using the same or a very similar approach to previous studies (e.g. Roth et al., 2013).

\subsection{Aim of the study}

The aim of this study is to capture the current state of users' expectations regarding interface elements and their positioning on three different website types. To gain these insights, we applied the same approach as Roth et al. (2010). This study provides insights into (i) which interface elements are currently expected on a website; (ii) where users expect these interface elements to be positioned on different website types and (iii) how-by comparing our results to the study of Roth et al. (2010)—users' expectations about different types of websites might have changed over time based on the exposure to new website layouts.

\section{METHODS}

This study, with the overall goal to investigate the change over time of users' mental representations of websites, reports the results of participants from German-speaking countries (Germany, Austria and Switzerland; further abbreviated as $\mathrm{DACH})$ and the USA. This sample was comparable to a previous sample investigated in 2007 (Roth et al., 2010), allowing us to directly compare their results to ours and thereby illustrate potential changes in users' mental representations over time.

\subsection{Design of the study}

We assessed users' mental representations in an online study by asking participants to sketch their prototypical mental image of each of three different website types using a predefined set of interface elements as building blocks.

\subsubsection{Stimuli selection procedure}

In order to select the most frequent and most representative website types for our study, two independent coders categorized the 100 most frequently visited websites in DACH and the USA. Website traffic information was retrieved from Alexa.com (Alexa Internet, 2013). In a first step, the two coders categorized the websites independently of each other and in a second step they compared their categorizations and discussed discrepancies until they reached a consensus. Across all countries, the following categories occurred most frequently: company websites $(19 \%)$, news websites $(15 \%)$, online shops $(9 \%)$, social networking sites $(7 \%)$ and search engines $(13 \%)$. The remaining websites $(38 \%)$ were categorized into various smaller groups. Table 1 gives an overview of the website types identified in Roth et al. (2010) and in our study. The numbers of online shops and news websites in the top 100 websites have increased compared to the study of Roth et al. (2010), whereas the number of company websites has decreased. We excluded social networking sites such as Facebook and Twitter because without login they grant only limited access to the main page and we excluded search engine websites such as Yahoo and Google because they have a very simple start page layout. Furthermore, we excluded the remaining websites in the category 'other' because of either their infrequent appearance, the high number of sub-categories, or unclear classification not allowing a meaningful comparison and analysis.

Table 1. Categorization of the top 100 websites (traffic-based, Alexa.com) into website types.

\begin{tabular}{lcc} 
Type of website & 2007 & 2014 \\
Company websites & 35 & 19 \\
News websites & 10 & 15 \\
Online shops & 5 & 9 \\
Search engines & 5 & 13 \\
Social networking sites & 30 & 7 \\
Other & 15 & 38 \\
\hline
\end{tabular}

Numbers represent percentage of occurrence. 
After categorizing the websites, each interface element on the start pages of the websites of all online shops, news websites and company pages was identified. An overview of the interface elements with their description can be found in Appendix 1 and as part of the supplementary materials provided online (http://iwc.oxfordjournals.org/lookup/suppl/ doi:10.1093/iwc/iww012/-/DC1). A total of 44 interface elements could be identified (see Table 2 for details). We reduced the number of interface elements to be included in the main study by conducting an online survey on crowdflower.com with 49 participants from the $\mathrm{DACH}$ region and 47 participants from the USA. For each website type, the 25 most frequently identified elements were presented in randomized order and participants indicated which of these elements they would expect to find on a typical website. The 18 most frequently selected interface elements that were selected by at least $40 \%$ of the participants per country were included as building blocks for the main study. For the DACH region and the US sample, there were different elements included as building blocks.

\subsection{Participants}

Participants were recruited online via crowdflower.com and received US\$ 1.70 as compensation. Additionally, to support recruitment in German-speaking countries, the Psychology Departments' participant pool, mailing lists and social networks were used to further promote the survey, with a raffle of three vouchers (US\$ 30 each) offered as compensation.

The online study was started by 649 (DACH version) and 485 participants (US version); it was completed by 530 (DACH) and 428 (the USA) participants. We excluded participants who either did not complete the survey or did not correctly answer the verification questions at the end of the survey. The verification questions required participants to describe the purpose of the study without being able to go back and check the survey again. Additionally, we excluded participants who took less than a minimum of 100 seconds to sketch the three website types. We used this threshold, based on results of several pilot trials, to exclude participants who might have been just clicking through the study. In the end, we were able to use the data of 841 participants (459 DACH and 382 USA) for further analysis (313 female, 524 male, 4 no answer provided).

The 459 participants for the German-speaking area were from Germany (77.1\%), Switzerland (5.9\%) and Austria (9.4\%); the remaining $7.6 \%$ of participants were from other countries. For the US sample, $96.1 \%$ named USA as their country of origin, the remaining participants coming from Canada $(<1.0 \%)$, China $(<1.0 \%)$, Iraq $(<1.0 \%)$, Mexico $(<1.0 \%)$ and Trinidad and Tobago $(<1.0 \%)$. Overall, our sample was well-educated and experienced Internet users, as nearly all participants reported using the Internet on a daily basis. For detailed information about the demographical data of the participants, see Table 3 .
Table 2. Overview of the different interface elements and their frequency for each website type in 2014 in alphabetical order.

\begin{tabular}{|c|c|c|c|}
\hline Element & $\begin{array}{l}\text { Company } \\
\text { page }(\%)\end{array}$ & $\begin{array}{c}\text { News } \\
\text { website } \\
(\%)\end{array}$ & $\begin{array}{l}\text { Shop } \\
(\%)\end{array}$ \\
\hline About us & 91 & $64^{\mathrm{b}}$ & 84 \\
\hline Accessibility & $45^{\mathrm{b}}$ & - & - \\
\hline Advertisement & 24 & 46 & 30 \\
\hline Archive & - & $80^{\mathrm{a}}$ & - \\
\hline Certifications & $47^{\mathrm{b}}$ & - & - \\
\hline Contact & 90 & 76 & 92 \\
\hline Cookies & 30 & 33 & $36^{\mathrm{b}}$ \\
\hline Create ad & - & 36 & 20 \\
\hline Deals and recommendation & $28^{\mathrm{b}}$ & - & 75 \\
\hline e-Paper & - & $61^{\mathrm{a}}$ & - \\
\hline FAQ & - & - & - \\
\hline Feedback & - & $49^{\mathrm{b}}$ & - \\
\hline Forum & 26 & 45 & 25 \\
\hline Guestbook & - & - & - \\
\hline Help & 69 & 56 & 81 \\
\hline Home & $84^{\mathrm{a}}$ & 83 & - \\
\hline Hotline & $67^{\mathrm{a}}$ & & $76^{\mathrm{a}}$ \\
\hline Jobs & 68 & 52 & 28 \\
\hline Language country selection & 63 & $38^{\mathrm{b}}$ & 60 \\
\hline Last updated & - & $68^{\mathrm{b}}$ & - \\
\hline Legal information & 65 & 53 & 72 \\
\hline Login or register & 45 & 55 & 84 \\
\hline Logo & 89 & 70 & 83 \\
\hline Main area & 79 & 74 & 82 \\
\hline Mobile version & 44 & 54 & $66^{\mathrm{b}}$ \\
\hline Main navigation area & 78 & 74 & 75 \\
\hline Newsletter & - & $69^{\mathrm{a}}$ & - \\
\hline Partner & 44 & $29^{\mathrm{a}}$ & 26 \\
\hline Payment & - & - & - \\
\hline Press releases & $41^{\mathrm{a}}$ & - & 14 \\
\hline Privacy & 73 & 60 & 71 \\
\hline Rich footer & 49 & 45 & 46 \\
\hline RSS & - & 51 & - \\
\hline Search & 68 & 76 & 80 \\
\hline Security & $\mathbf{5 5}^{\mathrm{b}}$ & - & - \\
\hline Shipping cost & - & - & 90 \\
\hline Shopping cart & $49^{\mathrm{a}}$ & - & 89 \\
\hline Sitemap & 63 & $68^{b}$ & - \\
\hline Social networks & 41 & 55 & 38 \\
\hline Subarea & - & - & - \\
\hline Sub-navigation & 50 & 44 & 51 \\
\hline Subscription & - & $64^{\mathrm{a}}$ & - \\
\hline Wishlist & - & - & $61^{\mathrm{a}}$ \\
\hline
\end{tabular}

The 18 interface elements included in the main study are marked in bold. A N-dash indicates that an element was placed by $<1 \%$ of the participants.

${ }^{\mathrm{a} O n l y}$ in the USA.

${ }^{\mathrm{b}}$ Only in DACH. 
Table 3. Demographic data of participants.

\begin{tabular}{|c|c|c|c|c|}
\hline & M & SD & $\%$ & Range \\
\hline Age (in years) & 35.1 & 11.6 & & \\
\hline DACH & 35.0 & 12.0 & & $14-69$ \\
\hline The USA & 35.3 & 11.2 & & $18-71$ \\
\hline \multicolumn{5}{|l|}{ Time to fill in study (in minutes) } \\
\hline $\mathrm{DACH}$ & 18.1 & 9.7 & & \\
\hline The USA & 17.4 & 10 & & \\
\hline Level of education & 3.4 & 1.1 & & \\
\hline Normal education (primary school) or equivalent & & & 5.8 & \\
\hline Apprenticeship or equivalent & & & 10.5 & \\
\hline Intermediate education (secondary school) or equivalent & & & 11.9 & \\
\hline Higher education (vocational school and diplomas) or equivalent & & & 32.0 & \\
\hline University degree or equivalent & & & 38.9 & \\
\hline Other & & & 1.0 & \\
\hline Experience using the computer ${ }^{\mathrm{a}}$ & 5.5 & 1.3 & & \\
\hline Experience using the Internet $^{\mathrm{a}}$ & 5.6 & 1.3 & & \\
\hline Experience in web design ${ }^{a}$ & 3.1 & 1.6 & & \\
\hline Frequency of Internet use for private reasons ${ }^{\mathrm{b}}$ & 5.8 & 0.8 & & \\
\hline Frequency of Internet use for professional reasons ${ }^{b}$ & 4.7 & 1.9 & & \\
\hline \multicolumn{5}{|l|}{ Frequency of ${ }^{\mathrm{b}} \ldots$} \\
\hline ...doing online shopping & 3.2 & 1.2 & & \\
\hline ...searching information on company page & 3.7 & 1.4 & & \\
\hline ...reading an online newspaper & 4.2 & 1.7 & & \\
\hline ...visiting a web portal & 4.3 & 1.7 & & \\
\hline
\end{tabular}

${ }^{a} 1$, very low; 7 , very high.

${ }^{\mathrm{b}} 1$, never; 2, 1-11 times per year; 3, 1-4 days a month; 4, 1-3 days a week; 5, 4-6 days a week; 6, every day.

\subsection{Procedure of the study}

The procedure of the main study is illustrated in Fig. 1 and was identical for all countries. The study was divided into three parts.

In the first part, at the beginning of the online questionnaire, participants were presented with a short demographic questionnaire followed by instructions on how to use the sketching application (text-based and within an instructional video). Participants were then forwarded to the training version of the sketching application where they could familiarize themselves with the features of the application by fitting furniture items into a bedroom floor plan. At the left side of the main sketching screen, a virtual browser window of $800 \times 520$ pixel was presented as the drawing canvas. The size of the canvas was chosen to represent frequently used screen sizes (StatCounter, 2013). On the right side, the interface elements identified in the preliminary study were presented as building bricks to compose the prototypical websites. The order of these elements was randomly generated for each participant. Figure 2 illustrates an example of a company website under composition by a participant.

Participants were asked to sketch each website type according to their expectations by placing the interface elements on the canvas by drag and drop. The instruction 'How does a typical online shop / company website / news website look

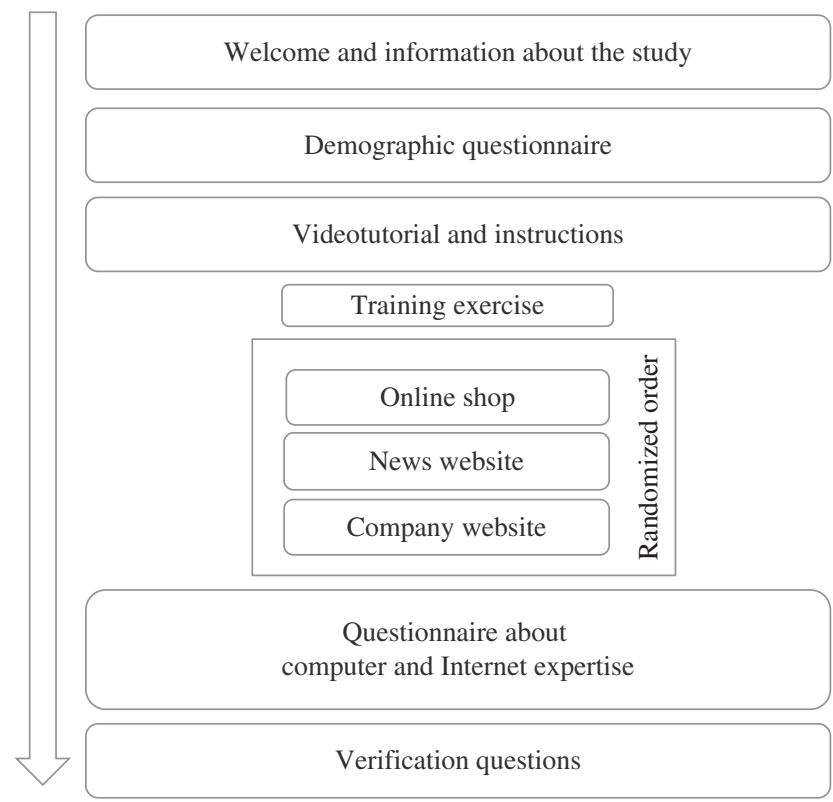

Figure 1. Schematic illustration of the procedure of the study.

to you? Use the elements within the blue box to build a typical online shop / company website / news website according to your expectations' was repeated at the top of each page. Tooltips revealed additional information for each interface 


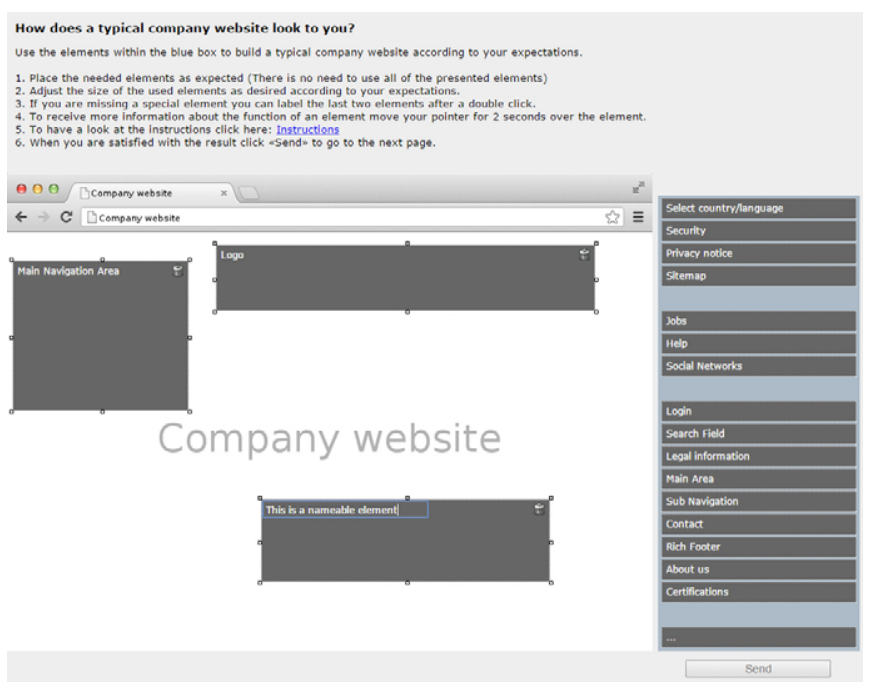

Figure 2. Screenshot of the sketching application.

element on mouse-over. All interface elements initially had the same size $(24 \mathrm{px} \times 240 \mathrm{px})$ but could be easily resized by drag and drop to match participants' expectations. Participants could additionally place two empty elements on the canvas area and label them. They used this option 113 times in total and the most frequently labeled element was related to advertising. Overall websites types, a total of 20 participants used this element. However, there was no clear pattern where participants placed these elements. Participants had to place a minimum of four elements before they could proceed to the next page and were randomly redirected to one of the remaining website types (online shop, news website and company website) to control for sequence effects. In the third part, the online questionnaire, participants were asked to answer questions concerning their computer usage and Internet knowledge and how frequently they used each of the three website types. Finally, to ensure the data quality, participants answered three verification questions where they had to decide whether certain questions had been part of the survey. After answering these verification questions, the study was completed and participants received the confirmation code to get their compensation on crowdflower.com.

\subsection{Data collection with the online sketching application}

To allow the participants to sketch their mental representations of websites, we used a multilingual web software that was especially developed for this purpose (Fraßeck, 2014). It runs in a web browser providing an interface for sketching different twodimensional objects in different languages (e.g. websites). It has a drag and drop API (application programming interface) to place objects on a virtual browser canvas. All technical details of the application are provided on the corresponding website (website Fraßeck, 2014). After submitting a final sketch of a website type, all objects are stored in an online database. Besides producing raw data of user sessions in CSV files, the software can process versatile visualizations of the submitted objects organized by website type, interface object, language and participant. Raw data will be provided as supplementary materials.

\subsubsection{Data preparation and data reduction to visualize}

For each participant and each website type, each interface element's positioning was recorded by saving the $x$ and $y$ coordinates, as was its height and width. We first analyzed the two samples separately, observing no differences in expectations. In order to compare our results with those of Roth et al. (2010), we pooled the DACH and US data, thereby investigating changes over time in users' expectations. Data were analyzed using SPSS 21 (IBM Corp., 2012) and R ( $\mathrm{R}$ Core Team, 2014). To visualize how participants placed the interface elements on the canvas, we generated contour maps based on the centroid of the elements. We did this for each element and each website type separately. The contour lines in the plots represent two-dimensional kernel density estimations that are calculated on the basis of the centroids of the elements and the dots represent the centroids of the elements. We used the kde2d function in MASS package (Venables and Ripley, 2002) to calculate the density estimations and the ggplot2 package (Wickham, 2009) to generate corresponding contour maps. The contour maps illustrate the density distribution of a certain interface element on the website canvas. The raw data of 2007 (Roth et al., 2010) were analyzed, and visualized using the same methods.

\section{RESULTS}

In the following section, we analyze (i) which interface elements users expect on websites and (ii) where they expect these elements to be located on the site. We obtained the data originally collected in 2007 (personal communication, 2013) from Roth et al. (2010). We compare the current expectations (i.e. 2014) to the expectations collected in 2007 (Roth et al., 2010).

\subsection{Interface elements users expect on a website}

Table 4 provides a complete overview of mean percentages by website type and study of participants placing an interface element on the canvas. This table also highlights that participants did not use all the interface elements presented to them in the study to build their websites.

From these placement frequencies, we infer that in the view of users not all elements seem to be equally important as part of a website. Overall website types, the most frequently placed interface elements in 2014 are about us, contact, help, login/register, logo, main area, main navigation area, privacy and search, similar to the 2007 findings. The location of each of these elements is described in Section 4.2. 


\subsubsection{Changes over time that affect all website types}

Table 4 also displays interface elements that were not included in 2007, but are now part of users' mental representations of a website. As indication of the expected customization of an online shop and a company page, participants placed an interface element to select the country or language. For the news website, this element was not placed, presumably because a newspaper is provided in one main language. Our data suggest that a switch to the mobile version of a website is expected on an online shop and a

Table 4. Overview of the interface elements and the frequency of their placement for each website type in 2007 and in 2014 (if available).

\begin{tabular}{|c|c|c|c|c|c|c|}
\hline \multirow[b]{2}{*}{ Interface element } & \multicolumn{2}{|c|}{$\begin{array}{l}\text { Online } \\
\text { shop (\%) }\end{array}$} & \multicolumn{2}{|c|}{$\begin{array}{l}\text { News } \\
\text { website (\%) }\end{array}$} & \multicolumn{2}{|c|}{$\begin{array}{l}\text { Company } \\
\text { website }(\%)\end{array}$} \\
\hline & 2007 & 2014 & 2007 & 2014 & 2007 & 2014 \\
\hline \multicolumn{7}{|l|}{ Elements placed in 2007 and 2014} \\
\hline About us & 75 & 77 & 71 & 31 & 91 & 84 \\
\hline Advertisement & 65 & & 66 & 32 & & \\
\hline Archive & & & 82 & 39 & 59 & \\
\hline Back to homepage & 81 & & 83 & $32 / 44$ & 88 & 41 \\
\hline Contact & 88 & 78 & 82 & 75 & 93 & 82 \\
\hline Help & 80 & 70 & 72 & 64 & 71 & 62 \\
\hline Login or register & 94 & 78 & 86 & 72 & & 30 \\
\hline Logo & 93 & 84 & 93 & 83 & 96 & 84 \\
\hline Main area & 90 & 83 & 90 & 84 & 91 & 83 \\
\hline Main navigation area & 74 & 74 & 75 & 73 & 74 & 72 \\
\hline Newsletter & 56 & & 66 & 41 & 70 & \\
\hline Privacy & 76 & 66 & 61 & 66 & 64 & 70 \\
\hline Search & 91 & 80 & 92 & 78 & 59 & 68 \\
\hline Shopping cart & 94 & 80 & & & & 30 \\
\hline Legal information (2010: Conditions of use) & 83 & 66 & 64 & 56 & 75 & 68 \\
\hline \multicolumn{7}{|l|}{2014 only } \\
\hline Certifications & & & & & & 15 \\
\hline Deals and recommendation & & 64 & & & & \\
\hline e-Paper & & & & 29 & & \\
\hline Forum & & & & 33 & & \\
\hline Hotline & & 40 & & & & 41 \\
\hline Jobs & & & & 58 & & 69 \\
\hline Language/country & & 52 & & & & 59 \\
\hline Last time updated & & & & 21 & & \\
\hline Mobile version & & 21 & & 53 & & \\
\hline Partner & & & & & & 30 \\
\hline Rich footer & & 40 & & & & 41 \\
\hline RSS & & & & 53 & & \\
\hline Security & & & & & & 19 \\
\hline Shipping cost & & 64 & & & & \\
\hline Sitemap & & & & 27 & & 61 \\
\hline Social networks & & 25 & & 28 & & 30 \\
\hline Sub-navigation & & 52 & & & & 48 \\
\hline Subscription & & & & 34 & & \\
\hline Wishlist & & 36 & & & & \\
\hline \multicolumn{7}{|l|}{2007} \\
\hline FAQ & 79 & & 62 & & 74 & \\
\hline Link-List (external Links) & 47 & & 60 & & 62 & \\
\hline To the top & 54 & & 57 & & 55 & \\
\hline
\end{tabular}

Note: Because data for DACH and the USA were pooled, there are more than 18 elements in the 2014 sample. 
news website, but not necessarily on a company website. One reason might be that looking up a product or news is frequently done while on the go. Jobs and a site map are only expected on news websites and company pages. Legal information, which was similar, but not completely identical to the conditions of use included in former studies, was expected on all websites by more than half of participants. The rich footer was expected on online shops and company pages, but not (yet) on news websites. The interface element social network was placed on all three website types. From Table 4, it can also be deduced that there are interface elements (such as link-lists with external links, to the top or $F A Q s$ ) placed in 2007 that were no longer expected to be on any website type in 2014 .

\subsubsection{Changes over time that are website-type specific}

As previous studies have reported, there are interface elements that are typical for the main purpose of a website (Roth et al., 2010). We now look at each website type in turn. In 2014, users frequently placed the interface elements deals and recommendations and shipping cost-an area where information about the shipping costs is displayed or linkedwhen sketching their prototypical online shop. Additionally, results suggest that other typical online shop elements such as shopping cart and login/register are still expected on an online shop website. On a typical news website, new elements expected by participants included the possibility of a $s u b$ scription, an indication of when the information was last updated, and the ability to use a Rich Site Summary (RSS) feed to export information. For our participants, a company page no longer has to include an archive. However, users expect to see a login/register area, a shopping cart, jobs and links to social network. As these elements were selected by more than $30 \%$ of users, this might be an indication that users expect company pages to be more service oriented and not only to provide static information about the company.

\subsection{Where do users expect the interface elements to be placed?}

In the next section, we visualize users' raw data for each interface element and website type. First, we give an overview of the currently expected location for the most frequently placed interface elements for all website types (see Figs 3-5). We only included elements that were placed for the DACH and the US sample. The dots represent the centroid of an element and the lines of the contour maps indicate the density of the elements. The more scattered the dots and the lower their density, the wider apart the lines are. This represents a less consistently expected location for these interface elements. On the other hand, a higher density of dots results in finer lines and can be interpreted as a more consistently expected location.
Where data were available in the data set of 2007 (Roth et al., 2010), we visualize the data identically and display the corresponding results next to each other. Two of the authors visually inspected each contour map and discussed its interpretation until agreement was reached.

\subsubsection{Interface elements in similar locations for all website types}

First, we look at interface elements that are consistently placed in a similar location across all or at least two website types. The $\log o$ is placed in the far left corner or at the center at the top of the website. The main area, where a website's content is displayed, is expected to be in the center of the website. To contact the owner of the website, users consistently expect to find this interface element at the bottom of the website, where they also expect the help to be found. Also, all legal information is expected at the bottom of the site, presumably within the rich footer area; however, as for the news website, the rich footer was not frequently enough selected in the preliminary study to be included in the main study and to enable us to reach a conclusion. When users search for something, they expect the search box to be located in the top right corner. They also expect the login or register area in this far right corner. When users want to change the language or country for the online shop or the company website, they expect to be able to do it in the top right corner.

There were some interface elements that were placed on all website types, but their expected location was not as consistent as for other elements. For all website types, the raw data for the links to social networks showed wider lines and less consistent positioning, indicating that users do not seem to have a specific expected location for this interface element yet. However, there is a tendency to place it in the top right area.

\subsubsection{Changes for interface elements locations for all website types}

Next, we compare the expected location of the interface elements to the data from 2007. Overall, results suggest that the positioning of elements has not fundamentally changed over the years, but there are some noteworthy differences. The location of interface elements such as the main content area, the logo and the navigation area has remained stable since 2007. It seems that the expected locations have become even more pronounced because participants agree more strongly on the locations of these elements than back in 2007. For instance, as can be seen in Fig. 3, the logo of an online shop is more consistently placed in the top left area. In 2007, contact was often placed on the left side of the website, probably revealing that contact information in previous designs used to be frequently integrated in the navigation area; however, in 2014 for all website types contact was placed in the bottom area of the website, most likely within the footer area. With regard to the navigation area, most users still placed it on the left side of the website. In 2014 there was also a tendency to 


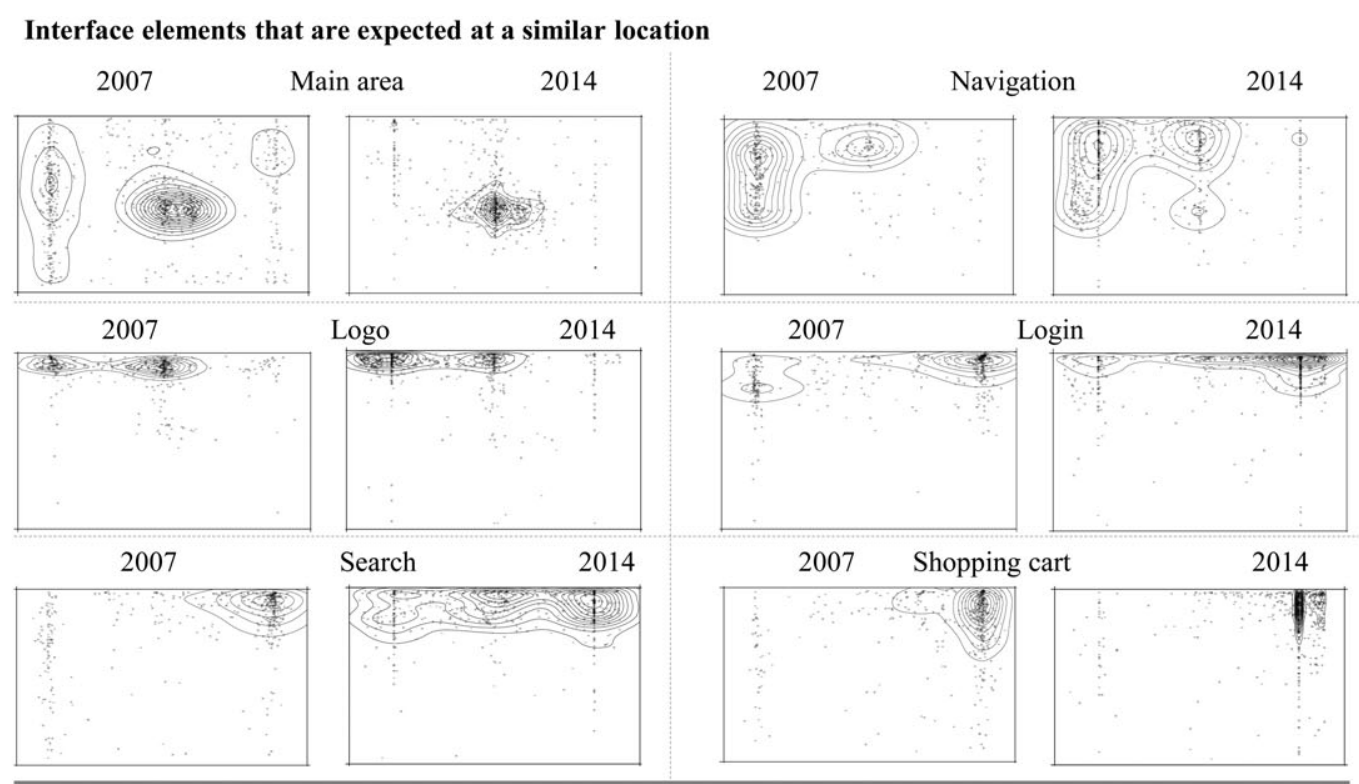

Interface elements that are expected at a different location

2007

About us

2014

2007

Legal information

2014
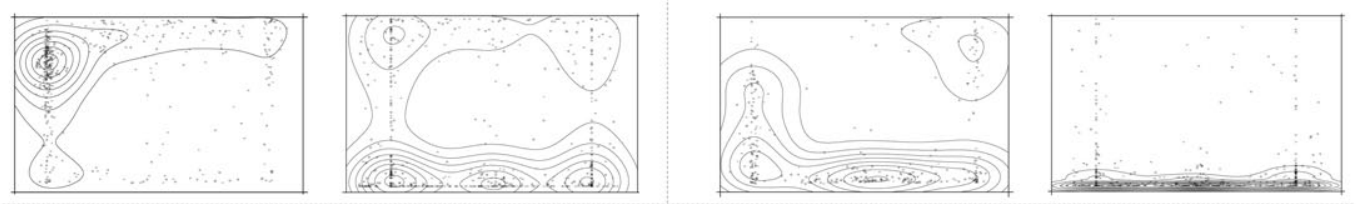

2007

Help

2014

2007

Contact

2014
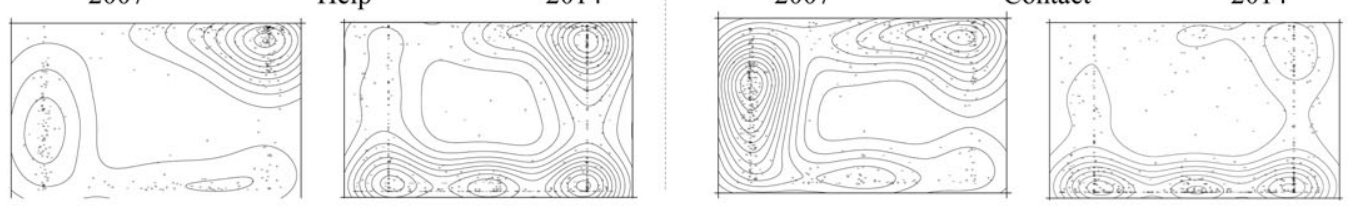

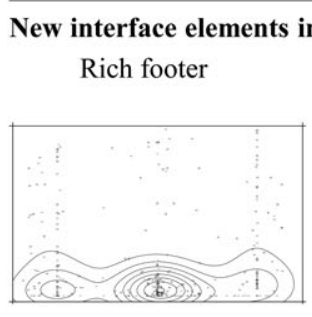

Deals and recommendations

Language or country selection
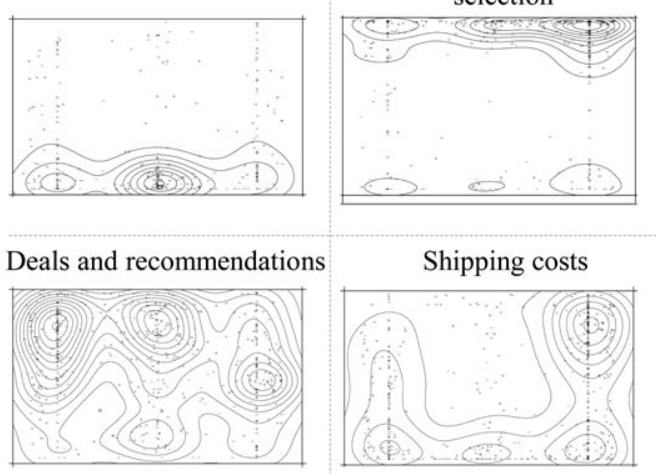

Shipping costs

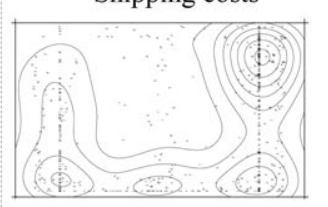

Wish list

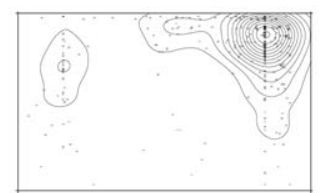

Mobile version

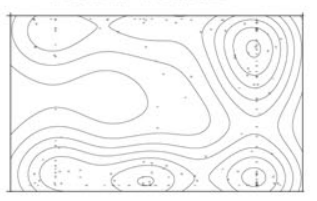

Social networks

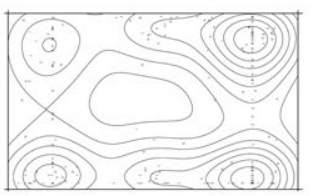

Hotline

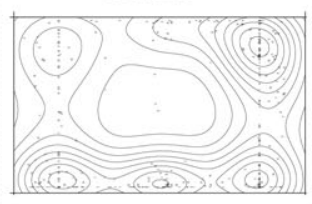

Figure 3. Expected locations of the most frequently placed interface elements from 2007 (Roth et al., 2010) (left) and the current study (right) for online shop.

expect the navigation area at the top towards the center of the website; this was not the case in 2007. The shift towards the center of the website might indicate that navigational interaction patterns using mouse-over animations and mega- fly outs (a big, two-dimensional drop-down panel) are more widely used and are incorporated in users' mental representations of websites. Websites designed for mobile devices also position interface elements centrally on the screen. 
Interface elements that are expected at a similar location

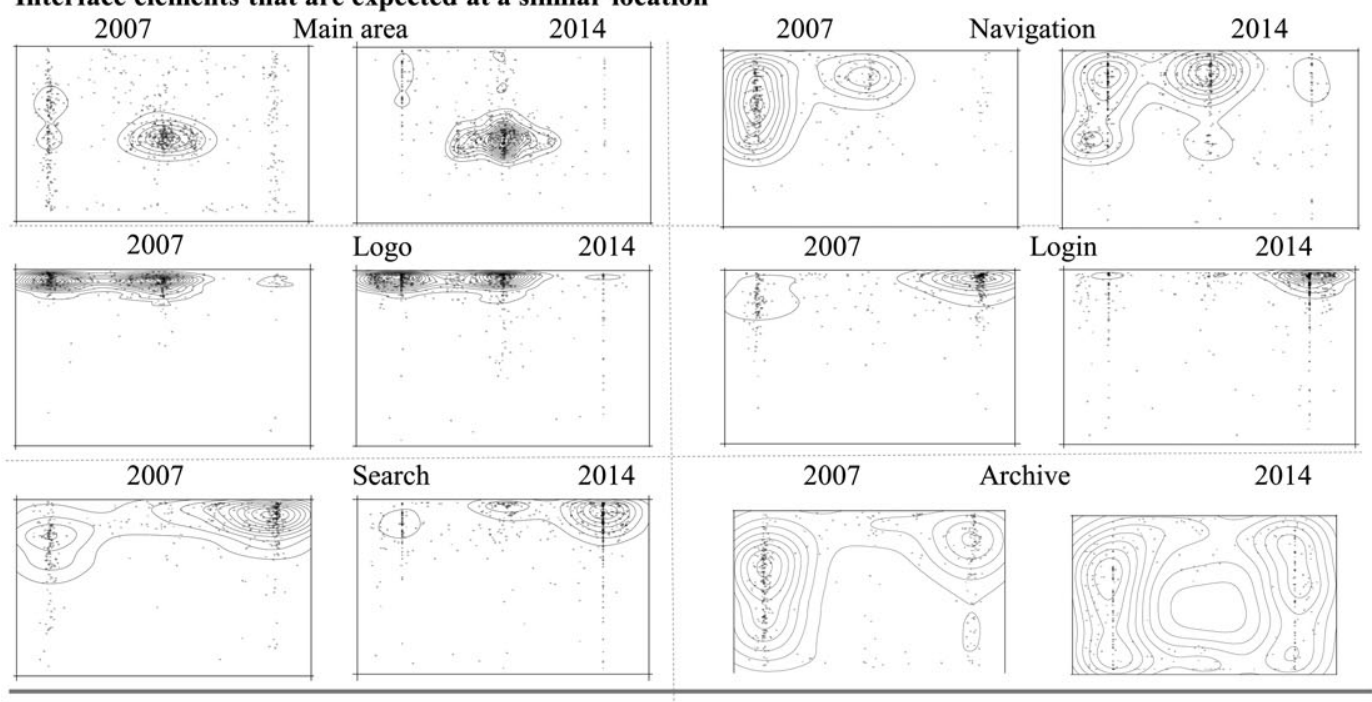

Interface elements that are expected at a different location
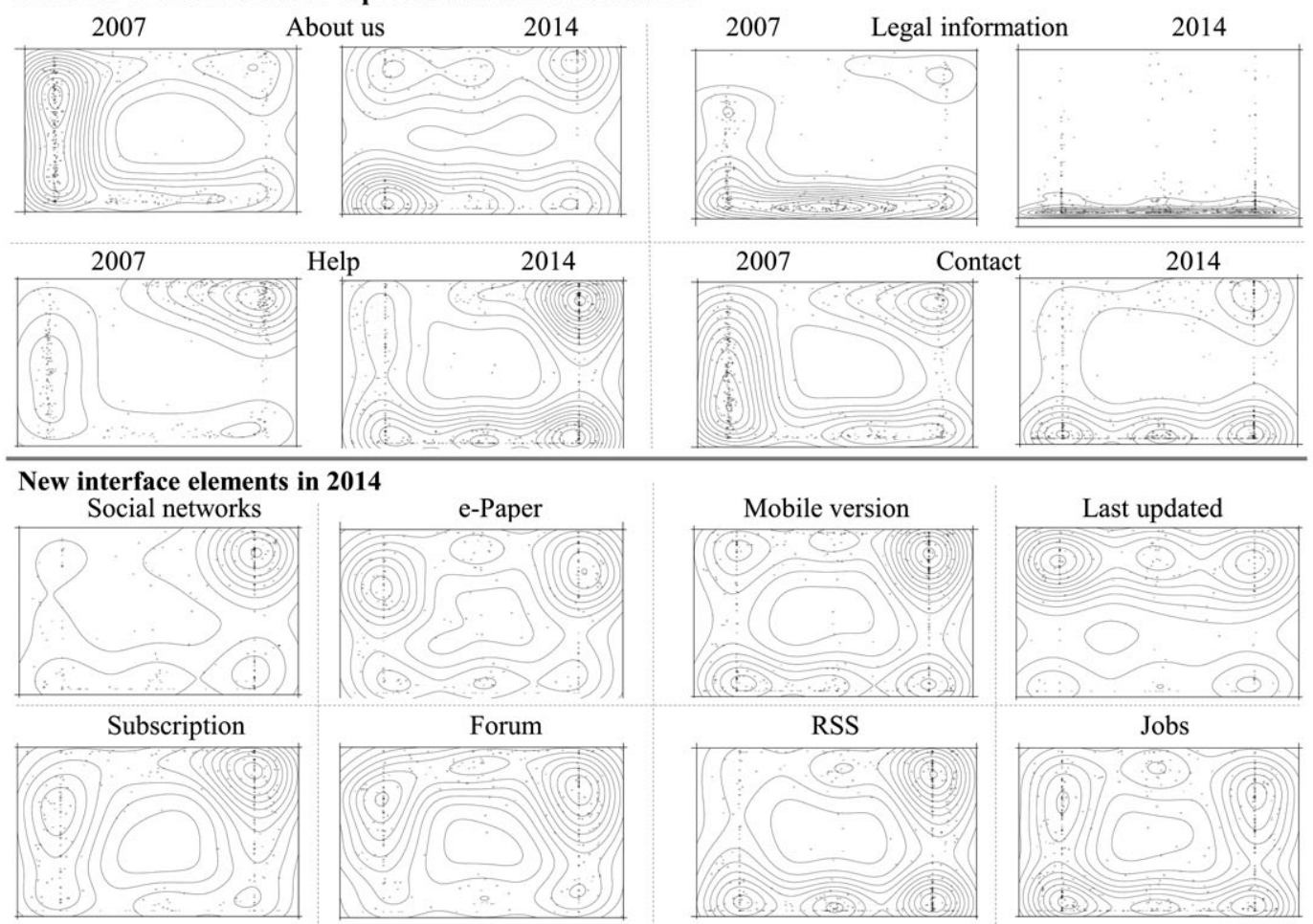

RSS
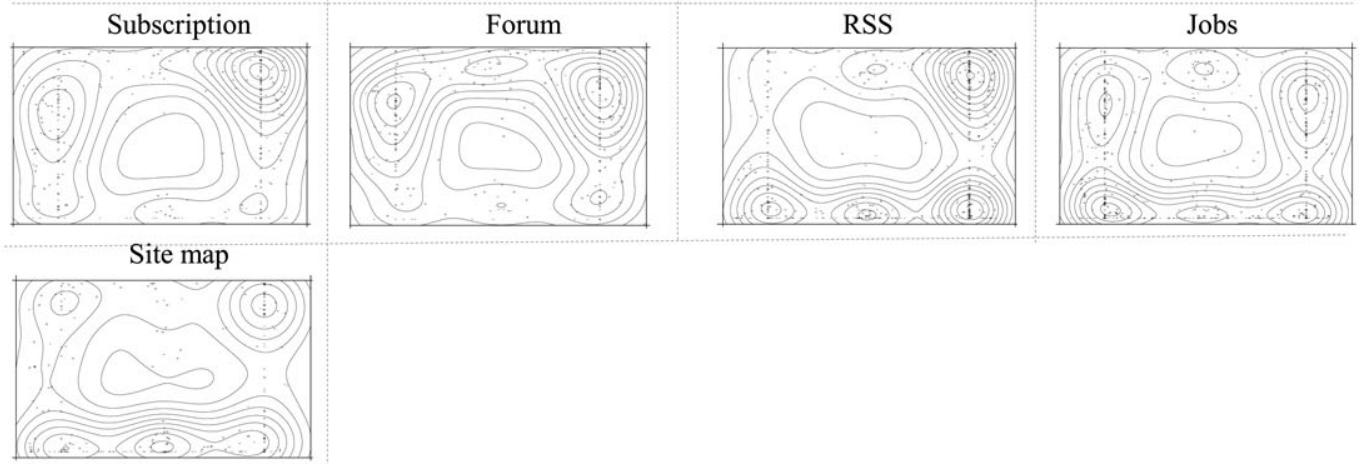

Figure 4. Expected locations of the most frequently placed interface elements from 2007 (Roth et al., 2010) (left) and the current study (right) for online newspaper.

\subsubsection{Changes for interface elements on specific website types}

Results indicate that there are no interface elements that have changed their location for specific website types only; however, for each website type there are new interface elements that were incorporated into users' mental representations. For the online shop, wish list is an element that was not included in the previous results of 2007 but was included in 

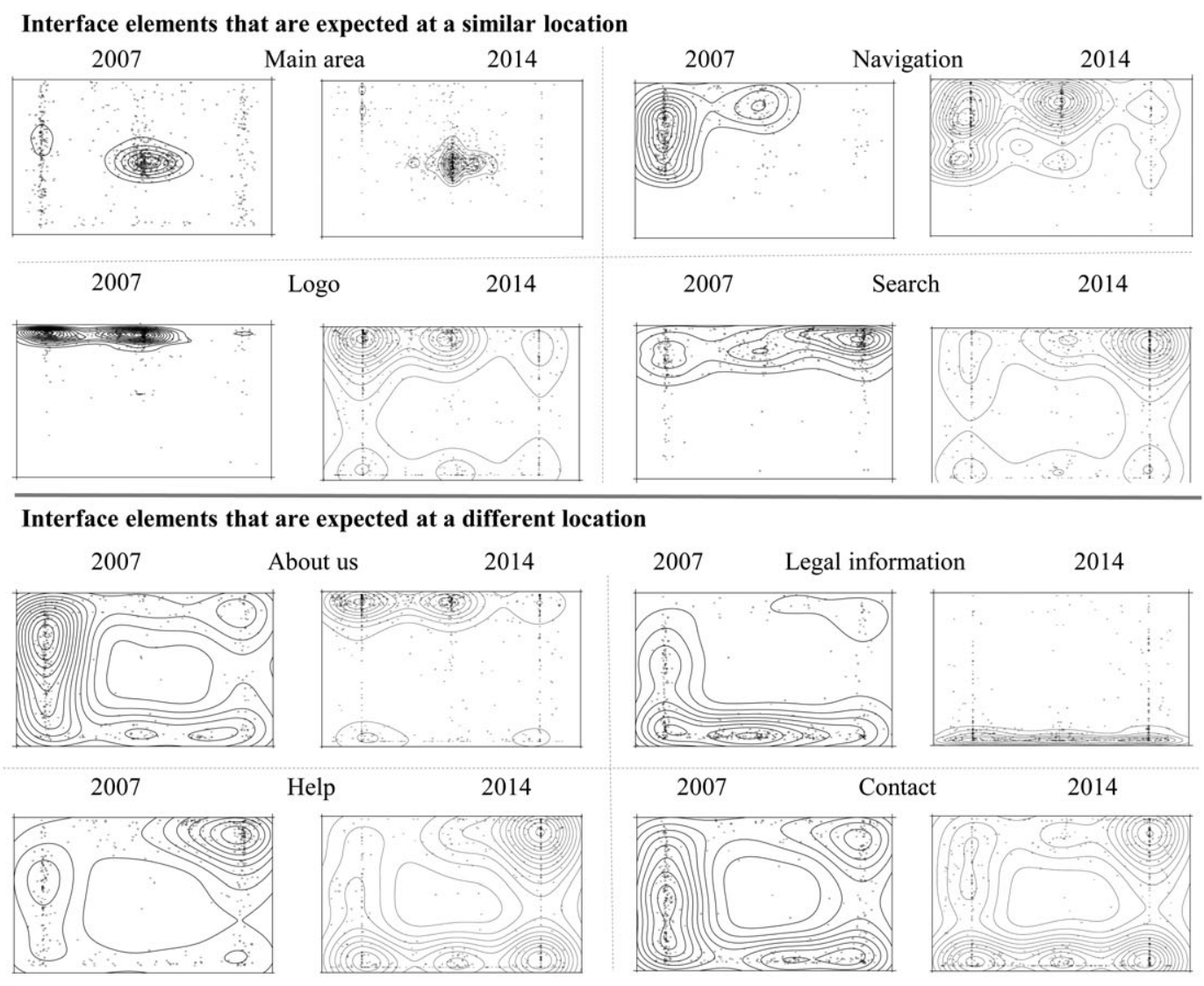

New interface elements in 2014

Social Networks

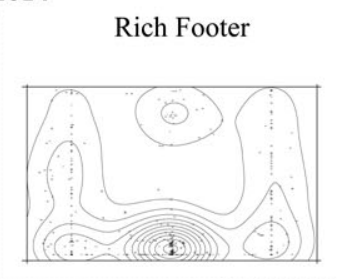

Language and country

Shopping Cart

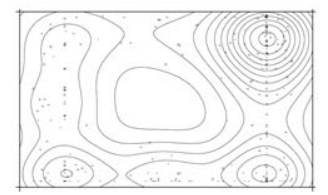

selection

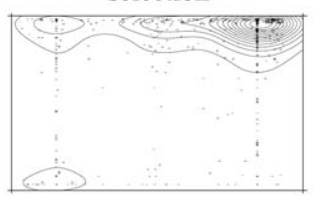

Partner
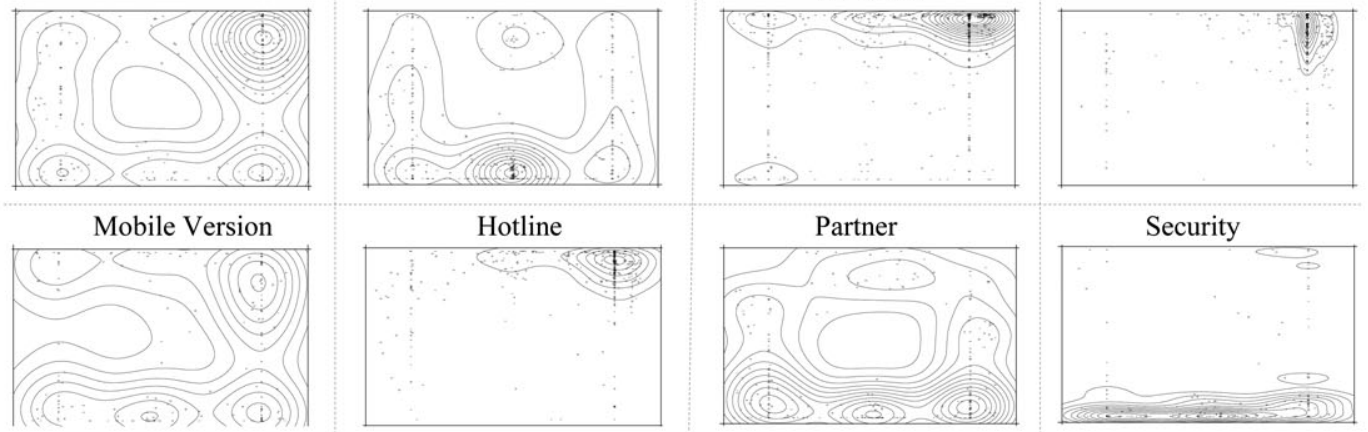

Jobs
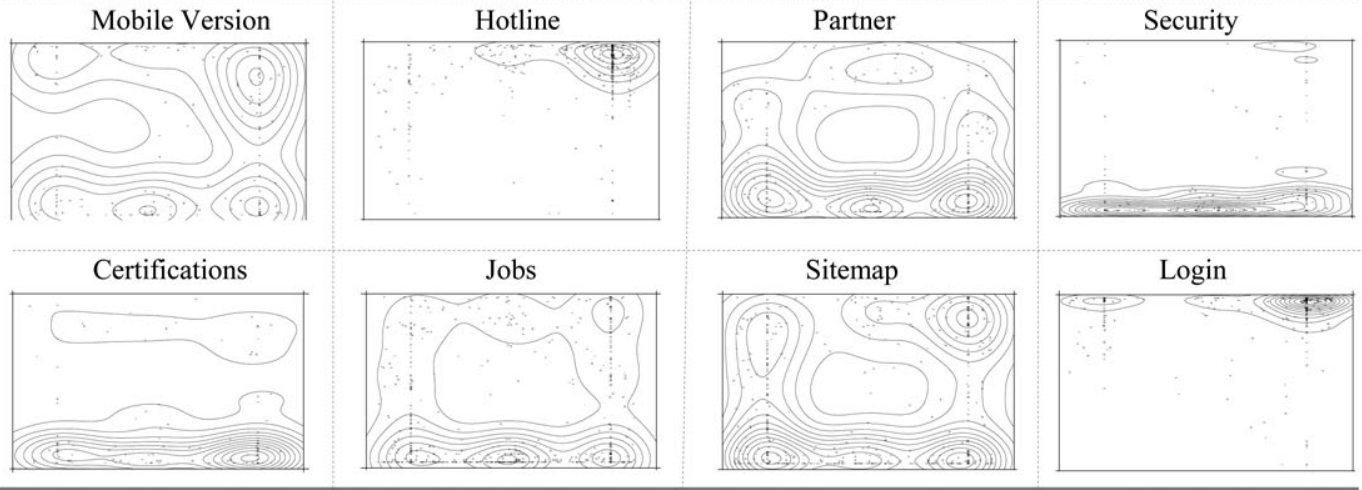

Figure 5. Expected locations of the most frequently placed interface elements from 2007 (Roth et al., 2010) (left) and the current study (right) for company pages.

the present study. Users expect it in the top right corner of the website, where the country selection is also expected. On a typical news website, the mobile version seems to be an important new element, but there is no consensus where on the site it is expected. As visualized in Fig. 4, the e-Paper (electronic version) of a newspaper and the indication of when the site was last updated are accordingly not yet expected in one distinct location. For the company website, 
users in 2014 expected to find information about the company in the about us element at the bottom of the website. This is different to its placement in 2007, when the information was expected within the navigation area of a website. As illustrated in Fig. 5, if users wish to get in touch with the hotline they seem to expect this interface element to be located either next to contact in the top right corner or within the footer area.

\subsection{What do users expect a prototypical website to look like?}

One aim of this study is to provide guidelines for website designers to know where website users expect specific interface elements to be located. We therefore summarize the results of all interface elements for each website type in aggregated blueprints. To do so, two researchers visually compared the contour maps for each interface element and decided on the most typical location for each. If results were ambiguous or indicated several possible locations, the two researchers placed the elements to result in a balanced layout. The most pronounced location for each interface element was integrated in a blueprint, as an approximation of the contour maps. To visually illustrate the overall changes over time, we juxtapose the blueprint models from 2007 [adopted from Roth et al. (2010) to our blueprints from 2014] (Figs 6-8). The new elements in the blueprints for 2014 are highlighted in gray.

As discussed in previous sections, compared to 2007 several new interface elements are expected to be found on each website type; for example links to social networks are expected on all website types. The expected location of several interface elements such as contact, privacy information, legal information or help seems to have transferred to the bottom of the page, presumably within the rich footer area. This rich footer has been integrated into the blueprint for the online shop and the company page, but not for the news website (users did not select this interface element frequently enough in the preliminary study for it to be included in the main study).

For the online shop displayed in Fig. 6, we integrated new interface elements such as wish list, deals and recommendations. According to the contour maps, whereas in 2007 search was placed in the center of the page, in 2014 it was placed towards the top right corner. In Fig. 7, new elements for news websites were mobile version and e-version. These elements were placed on either the right or the left side of the website. The indication of when the website was last updated was expected to be on the top of the site. For the company page, jobs, mobile version and hotline were integrated into the blueprint model in Fig. 8.

\section{DISCUSSION}

In this study, we investigated which interface elements are expected on different website types, and where users expect

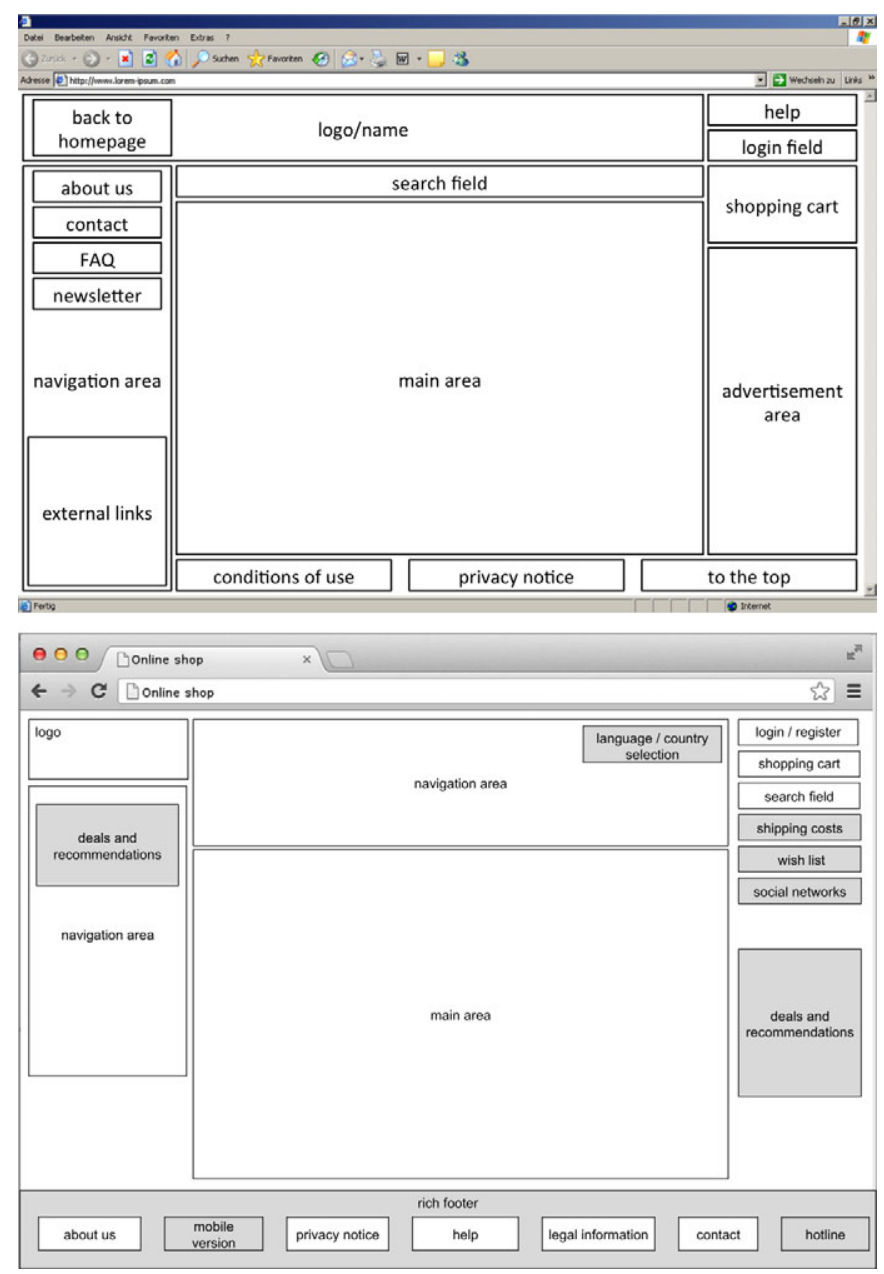

Figure 6. Blueprint model for an online shop in 2007 (top) and 2014 (bottom).

them to be located. Moreover, we compared our results to data from 2007 in order to investigate differences in expected interface elements over time. Results suggest that there are interface elements that users expect to find on all the three types of websites we analyzed (i.e. online shopping, company website, news website). These are core interface elements of a website, such as the main area, navigation area or the search box, but also elements containing information regarding the owner of the website such as the logo, about us or contact. These results are consistent with previous studies that investigated the design of websites and the layout of interface elements (Cassidy and Hamilton, 2014). Overall, it seems users' expectations about these interface elements have not changed since 2007 (Roth et al., 2010). These are relevant interface elements of any website and have been shown in other studies to be the most important for a website (Cassidy and Hamilton, 2014). In regard to other elements, however, users' expectations have changed. On today's website, users expect social media and personalization elements such as links to social networks, wish lists or areas to login or register. Due 


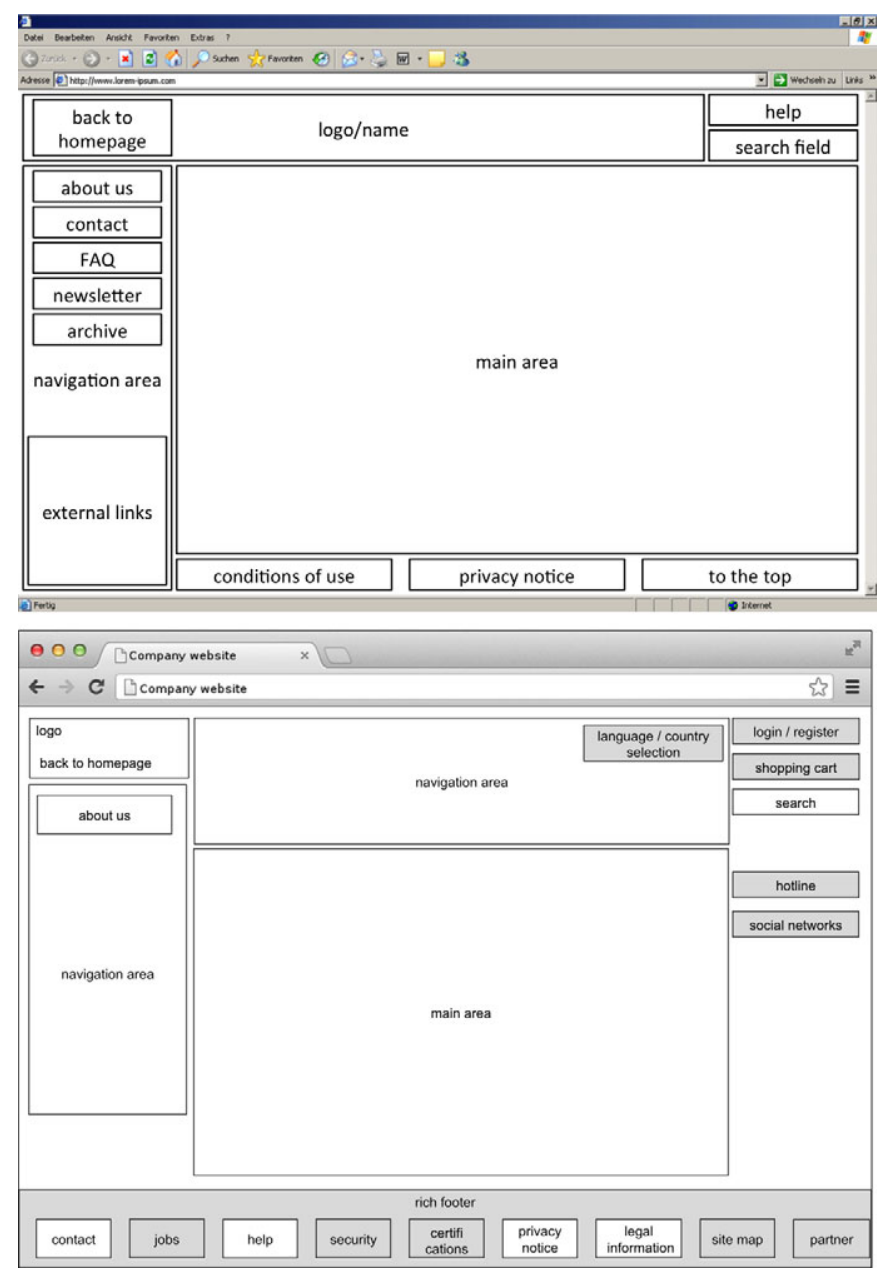

Figure 7. Blueprint model for a company website in 2007 (top) and 2014 (bottom).

to technological advances in the mobile device field, interface elements such as a mobile version of a website or an $e$-version of an online newspaper are now expected on a website.

There are also interface elements that are no longer part of the users' mental representations of a website. Among these are elements that allow the user to navigate within a webpage such as a link leading to the top. This might be explained by the use of horizontal scrolling or the willingness of users to scroll on websites and new navigation habits. In 2014, advertisements are no longer expected to be on websites. One explanation might be that ads are undesired and were therefore not selected. Moreover, FAQs are not expected on any of the website types. One reason might be that users find other ways such as search engines, social networks or specialized knowledge sites to find answers to their questions.

With regard to users' expectations about the concrete location of elements on websites, we were able to observe some changes between 2007 and 2014, but only for a small number of elements. We infer from this that users' mental

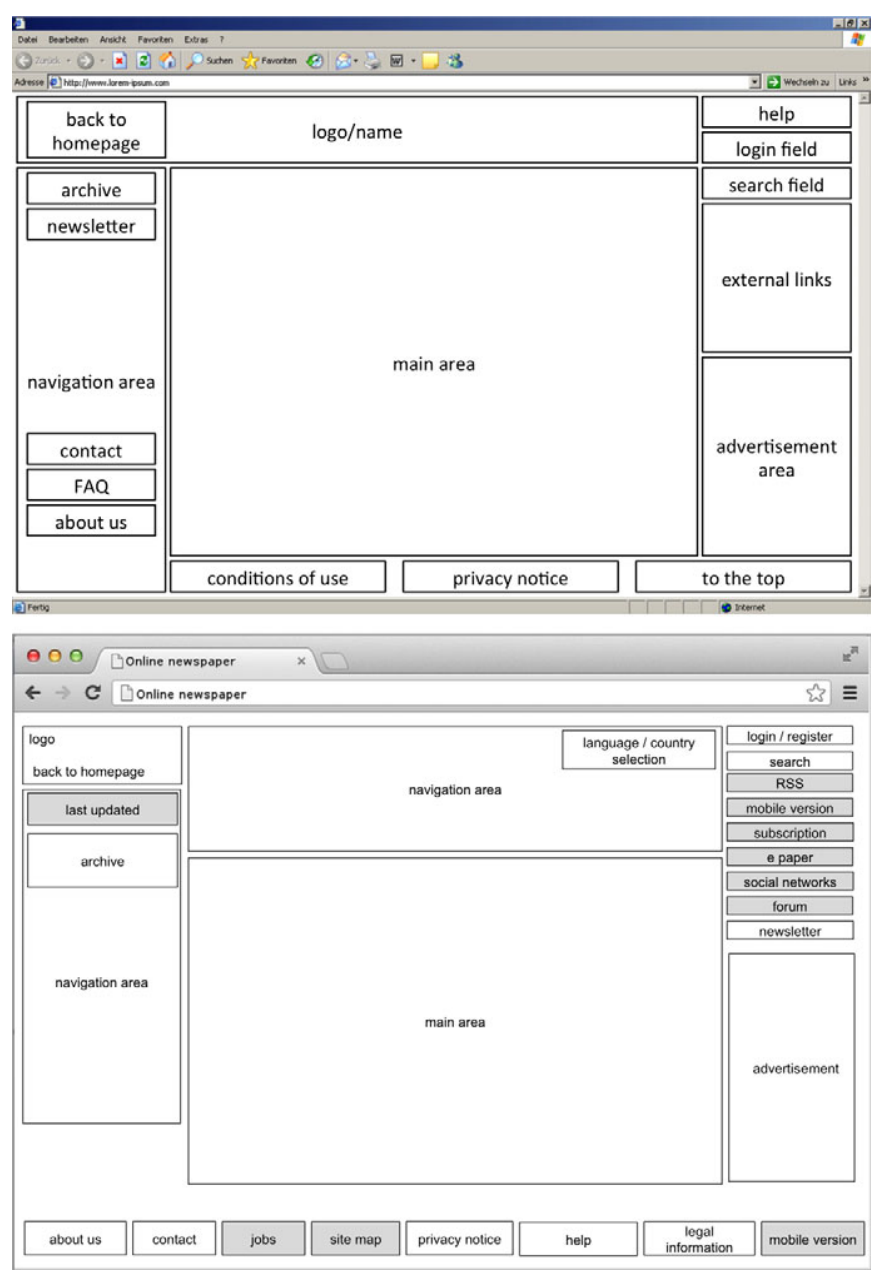

Figure 8. Blueprint model for an online newspaper in 2007 (top) and 2014 (bottom).

representations of websites are relatively stable over time. The location for most core interface elements (such as main content, logo and search) remained unchanged; however, the location for other elements (such as contact and help) has moved towards the bottom of the page. In a similar study, Shaikh et al. (2006) compared users' mental representations of websites between 2001 and 2006. They observed changes in location expectation for internal links (i.e. navigation), search and ads. In our study, however, the expected location for the navigation area as well as search remained unchanged over time. We were able to identify more consistent location expectations for legal information. Albert et al. (2009) were able to show similar trends for more consistent user expectations for home, search and the navigation area compared to previous results.

Our preliminary study about which elements users expect and our main study about the expected location of these interface elements suggest that users' mental representations seem to include new interface elements that are frequently used in website design and often encountered such as mouse-over navigation and the rich footer. This is manifested by an 
expansion towards the top right for the navigation area and several interface elements now expected to be found at the bottom of the website across website types.

Some of the new elements are very website specific such as shipping costs but were nonetheless placed by a substantial number of users. One explanation could be that there are some leading websites (such as Amazon for online shops) for each website type. These sites are frequently visited by users and if these major websites introduce certain new web design elements, the users' mental representations of this specific website type are affected by elements encountered on this prototypical site.

\subsection{Limitations}

As with any empirical study, there are certain limitations to our study, which we would like to point out. One drawback of the online survey used here was that it included many elements and website types, meaning that participants could not be asked why they placed each interface element in a certain location without the following drawbacks: they would be pulled out of their task which could increase the time spent filling in the survey and in turn could increase the number of dropouts. Furthermore, asking participants to sketch a prototypical website can result in users drawing how they imagine a website or how they would wish an ideal website to be (Volkamer and Renaud, 2013). Second, the generalizability of our results is to a certain extent limited by the focus on three website types only. As more and more diverse social network sites appear in the top websites, it would be interesting to see whether a representation of a prototypical social network website has formed in the minds of users.

Third, we recruited the participants to our studies using a crowdsourcing platform. This might have had an effect on the participants' motivation and demographic distribution such as education, and web experience in general compared to other recruiting channels. However, Weinberg et al. (2014) compared data of panels and crowdsourcing platforms and were able to show that data quality is even better when using crowdsourcing. Finally, in order to compare our results to previous studies (Bernard, 2001a, 2003; Bernard and Sheshadri, 2004; Roth et al., 2010), we only allowed participants to complete the study on a desktop computer or notebook thus excluding mobile devices. This is clearly a limitation as we cannot make statements about users' expectations of the three website types in their mobile version. To the authors' knowledge, no study has been conducted to show the expected location of interface elements on the small screens of mobile phones or tablets using some kind of drawing approach. Previous research has shown a positive influence of the agreement of a smartphone interface with users' mental models on perceived usefulness and ease of use (Jung and Yim, 2015). Therefore it would be interesting to see whether mental models for the layout of interfaces on mobile or tablet screens exist and how these mental models are influenced by design trends and guidelines of the most common operating systems.

\subsection{Conclusion and future research}

As more and more companies rely on their Internet presence and the success of many e-commerce websites depends on their users being able to navigate their website, it is necessary to understand what users expect from specific types of websites. Consequently, the goal of this paper is to (i) assess interface elements users expect to find on different types of websites, (ii) visualize where Internet users would expect these interface elements to be placed and (iii) to show similarities and differences to previous studies.

This paper makes a contribution in terms of highlighting the dynamic and stable elements in users' current prototypical mental representations over time. We compared our current results to previous results of 2007 and these results suggest that, overall, users' mental representations of a typical online shop, news website and company page have remained stable over time. However, an interplay of trends in website design, technological developments and the adaptation of users' mental representations of websites has taken place. We were able to show that new elements such as a rich footer and mobile version of the website and interface elements such as links to social networks or wish lists are now part of users' mental representations of a prototypical website.

Our results suggest that website designers creating websites to meet users' expectations should still adhere to design conventions that have been established because Internet users seem to adapt to these conventions. The contour maps, together with the aggregated blueprint model, can support designers during the development process by showing where to place certain new interface elements to meet users' needs and expectations.

To get a better understanding of the dynamics of mental representations of websites, it would be interesting to investigate which websites influence users most; for instance, whether design changes in a popular website have a stronger impact on users' expectations than changes in less popular ones. Regarding the increasing internationalization of websites, cultural differences should be closely examined. Based on our preliminary work, we could see that different interface elements were expected on the three website types for the samples of DACH and the USA. Despite this, we could find no differences regarding the expected location of the single interface elements. However, additional data from regions with diverse cultural backgrounds and highly visible and distinctive characteristics such as different reading direction could be collected and analyzed in depth for differences. Furthermore, we believe that the influence of interfaces with prototypical or non-prototypical layouts on different long- 
term behavioral outcomes (such as overall customer satisfaction, willingness to buy products and customer loyalty, and therefore its impact on a company's success) should be investigated with additional studies.

\section{ACKNOWLEDGEMENTS}

This research was supported by University of Basel and University of Applied Sciences and Arts Northwestern Switzerland. We would like to thank Dr. Markus Stoecklin for the support and input for the analysis. Furthermore, we wish to thank all the students and coders and participants for their valuable work.

\section{REFERENCES}

Fraßeck, L. (2014) Chameleon 0.6: mental modelling software. Retrieved from https://mmi.psycho.unibas.ch/tools/.

Adkisson, H.P. (2002) Identifying De-Facto Standards for ECommerce Web Sites. In Professional Communication Conf., 2002. IPCC 2002. Proc. IEEE International, pp. 22-45. IEEE.

Albert, D., Mast, M. and Burmester, M. (2009) Nutzererwartungen zur Position von Interface-Elementen auf Webseiten im Internationalen Vergleich. In Berichtband des siebten Workshops des German Chapters der Usability Professionals Association eV, pp. 92-95. Fraunhofer, Stuttgart

Alexa Internet. (2013) Alexa.com. http://www.alexa.com/ (accessed December 09, 2014).

Auinger, A., Aistleithner, A., Kindermann, H. and Holzinger, A. (2011) Conformity With User Expectations on the Web: Are There Cultural Differences for Design Principles? In Marcus, A. (ed.), Design, User Experience, and Usability. Theory, Methods, Tools and Practice, pp. 3-12. Springer, Berlin Heidelberg.

Baharum, A. and Jaafar, A. (2013a) Generation Y Expectations for the Location of Web Objects. http://www.aicit.org/JDCTA/ ppl/JDCTA3644PPL.pdf (accessed December 08, 2014 ).

Baharum, A. and Jaafar, A. (2013b) Users' Expectation of Web Objects Location: Case Study of ASEAN Countries. In Zaman, H.B., Robinson, P., Olivier, P., Shih, T.K. and Velastin S. (eds.) Advances in Visual Informatics, pp. 383-395. Springer International Publishing.

Baharum, A. and Jaafar, A. (2013c) Users' Expectation of Web Objects Location: Case Study of ASEAN Countries. In Zaman, H.B., Robinson, P., Olivier, P., Shih, T.K. and Velastin S. (eds.) Advances in Visual Informatics, pp. 383-395. Springer International Publishing.

Baharum, A. and Jaafar, A. (2014) Generation Y expectations for the location of web objects. Int. J. Digit. Content Technol. Appl., 8, 81-89.

Bernard, M.L. (2001a) Developing schemas for the location of common web objects. Proc. Hum. Factors Ergon. Soc. Ann. Meet., 45, 1161-1165. http://doi.org/10.1177/154193120104501502.
Bernard, M.L. (2001b) User Expectations for the Location of Web Objects, p. 171. ACM Press. http://doi.org/10.1145/634067. 634171.

Bernard, M.L. (2003) Examining user expectations for the location of common e-commerce web objects. Proc. Hum. Factors Ergon. Soc. Ann. Meet., 47, 1356-1360. http://doi.org/10.1177/ 154193120304701108 (accessed January 05, 2015).

Bernard, M.L. and Sheshadri, A. (2004) Preliminary examination of global expectations of users' mental models for e-commerce web layouts. Usability News, 6. http://psychology.wichita.edu/surl/ usabilitynews/62/web_object_international.asp.

Bhattacherjee, A. (2001) Understanding information systems continuance: an expectation-confirmation model. MIS Q., 25, 351-370. http://doi.org/10.2307/3250921.

Cassidy, L. and Hamilton, J. (2014) Location of service industry web objects: developing a standard. ACIS. http://aut.researchgateway. ac.nz/handle/10292/8015 (accessed October 23, 2014).

Craik, K. (1943) The Nature of Explanation. 1943. Cambridge University Press, Cambridge.

Cyr, D. (2014) Return visits: a review of how Web site design can engender visitor loyalty. J. Inf. Technol., 29, 1-26. http://doi. org/10.1057/jit.2013.25.

Davidson, M.J., Dove, L. and Weltz, J. (1999) Mental models and usability. Depaul University, Cognitive Psychology, 404.

Dinet, J. and Kitajima, M. (2011) "Draw Me the Web": Impact of Mental Model of the Web on Information Search Performance of Young Users. In 23rd French Speaking Conf. Human-Computer Interaction, pp. 3:1-3:7. ACM, New York, NY. http://doi.org/ $10.1145 / 2044354.2044358$.

Di Nocera, F., Capponi, C. and Ferlazzo, F. (2004) Finding geometrical associations between meaningful objects in the web: a geostatistical approach. PsychNol. J., 2, 84-98.

Flavián, C., Guinalíu, M. and Gurrea, R. (2006) The role played by perceived usability, satisfaction and consumer trust on website loyalty. Inf. Manag., 43, 1-14. http://doi.org/10.1016/j.im. 2005.01.002.

Gentner, D. and Stevens, A. (1983) Mental models. Lawrence Erlbaum Associates, Hillsdale, NJ.

Gerrikagoitia, J.K., Castander, I., Rebón, F. and Alzua-Sorzabal, A. (2015) New trends of intelligent e-marketing based on web mining for E-shops. Proc. Soc. Behav. Sci., 175, 75-83. http:// doi.org/10.1016/j.sbspro.2015.01.1176.

Harinarayana, N.S. et al. (2011) Identifying the location of web objects: a study of library web sites. http://ir.inflibnet.ac.in/ handle/1944/1597 (accessed December 08, 2014).

Holman, L. (2011) Millennial students' mental models of search: implications for academic librarians and database developers. J. Acad. Libr., 37, 19-27. http://doi.org/10.1016/j.acalib.2010.10.003.

Huang, Z. and Benyoucef, M. (2013) From e-commerce to social commerce: a close look at design features. Electron. Commer. Res. Appl., 12, 246-259. http://doi.org/10.1016/j.elerap.2012.12.003.

IBM Corp. (2012) IBM SPSS Statistics for Mac, Version 21.0 [Mac]. EN. IBM Corp., Armonk, NY. 
ISO 9241-11(E). (1998) ISO Ergonomic requirements for office work with visual display terminal (VDT's)-Part 11: Guidance on usability.

Johnson-Laird, P.N. (1983) Mental Models: Towards a Cognitive Science of Language, Inference, and Consciousness. Harvard University Press, Cambridge, MA.

Jonassen, D.H. and Henning, P. (1996) Mental Models: Knowledge in the Head and Knowledge in the World. In Proc. 1996 Int. Conf. Learning Sciences, pp. 433-438. International Society of the Learning Sciences, Evanston, IL.

Jung, W. and Yim, H.R. (2015) The effects of mental model on the variables in the technology acceptance model. http://www.sersc. org/journals/IJMUE/vol10_no3_2015/17.pdf (accessed April 12, 2015).

Kim, H. and Fesenmaier, D.R. (2008) Persuasive design of destination web sites: an analysis of first impression. J. Travel Res., 47, 3-13.

Kienle, H.M. and Distante, D. (2014) Evolution of Web Systems. In Evolving Software Systems, Springer Berlin, Heidelberg, pp. 201-228.

Linxen, S., Heinz, S., Müller, L.J., Tuch, A.N. and Opwis, K. (2014) Mental Models for Web Objects in Different Cultural Settings. In CHI '14 Extended Abstracts on Human Factors in Computing Systems, pp. 2557-2562. ACM, New York, NY. http://doi.org/ $10.1145 / 2559206.2581209$.

Lynch, P.J. and Horton, S. (2008) Web Style Guide: Basic Design Principles for Creating Web sites. Yale University Press.

McCarthy, J.D., Sasse, M.A. and Riegelsberger, J. (2004) Could I have the Menu Please? An Eye Tracking Study of Design Conventions. In O’Neill, E., Palanque, P. and Johnson, P. (eds.), People and Computers XVII-Designing for Society, pp. 401-414. Springer, London.

Mlilo, S. and Thatcher, A. (2011) Mental Models: Have Users' Mental Models of Web Search Engines Improved in the Last Ten Years? In Harris, D. (ed.), Engineering Psychology and Cognitive Ergonomics, pp. 243-253. Springer, Berlin Heidelberg.

Nadkarni, S. and Gupta, R. (2007) A Task-Based Model of Perceived Website Complexity. MIS Q., 31, 501-524.

Naughton, R. and Agosto, D.E. (2012) Favorite websites: understanding prior knowledge of teens' mental models of public library websites for teens. Proc. Am. Soc. Inf. Sci. Technol., 49, 1-11. http://doi.org/10.1002/meet. 14504901109.

Neisser, U. (1976) Cognition and Reality: Principles and Implications of Cognitive Psychology, Vol. xiii. W H Freeman/ Times Books/Henry Holt \& Co., New York, NY.

Nielsen, J. (1999) Designing Web Usability: The Practice of Simplicity. New Riders Publishing, Thousand Oaks, CA.

Norman, D.A. (1983) Some Observations on Mental Models. In Mental Models, Vol. 1. pp. 7-14. L. Erlbaum Associates, Inc., Hillsdale, NJ.

O'Reilly, T. and Battelle, J. (2009) Web Squared: Web 2.0 Five Years On. O’Reilly Media, Inc.
Oulasvirta, A., Kärkkäinen, L. and Laarni, J. (2005) Expectations and memory in link search. Comput. Hum. Behav., 21, 773-789.

Owens, J.W. (2013) Getting the gist of websites: exploring the effects of display duration, size, and resolution. http://soar. wichita.edu/dspace/handle/10057/6728 (accessed July 11, 2014).

Owens, J.W., Palmer, E.M. and Chaparro, B.S. (2014) The pervasiveness of text advertising blindness. J. Usability Stud., 9, 51-69.

Palmer, J. (2002) Designing for web site usability. Computer, 35, 102-103. http://doi.org/10.1109/MC.2002.1016906.

Purwati, Y. (2011) Standard features of E-commerce user interface for the web. J. Arts Sci. Commer., 2, 77-87.

Qian, X., Yang, Y. and Gong, Y. (2011) The Art of Metaphor: A Method for Interface Design Based on Mental Models. In Proc. 10th Int. Conf. Virtual Reality Continuum and Its Applications in Industry, pp. 171-178. ACM, New York, NY. http://doi.org/10. $1145 / 2087756.2087780$.

Rapp, D.N. (2005) Mental Models: Theoretical Issues for Visualizations in Science Education. In Visualization in Science Education, pp. 43-60. Springer.

R Core Team. (2014) R: A Language and Environment for Statistical Computing. R Foundation for Statistical Computing, Vienna. http://www.R-project.org/ (accessed May 30, 2015).

Roth, S.P., Schmutz, P., Pauwels, S.L., Bargas-Avila, J.A. and Opwis, K. (2010) Mental models for web objects: where do users expect to find the most frequent objects in online shops, news portals, and company web pages? Interact. Comput., 22, 140-152. http://doi.org/10.1016/j.intcom.2009.10.004.

Roth, S.P., Tuch, A.N., Mekler, E.D., Bargas-Avila, J.A. and Opwis, K. (2013) Location matters, especially for non-salient features-an eye-tracking study on the effects of web object placement on different types of websites. Int. J. Hum. Comput. Stud., 71, 228-235. http://doi.org/10.1016/j.ijhcs.2012.09.001.

Santa-Maria, L. and Dyson, M.C. (2008) The Effect of Violating Visual Conventions of a Website on User Performance and Disorientation: How Bad Can It Be? In Proc. 26th Annual ACM Int. Conf. Design of Communication, pp. 47-54. ACM, New York, NY. http://doi.org/10.1145/1456536.1456547.

Shaikh, A.D., Chaparro, B.S. and Joshi, A. (2006) Indian Users' Expectations for the Location of Web Objects on Informational Websites. In Proc. Human Factors and Ergonomics Society Annual Meeting, Vol. 50. pp. 1922-1926. SAGE Publications.

Shaikh, A.D. and Lenz, K. (2006) Where's the search? Reexamining user expectations of web objects. Usability News, 8. http://psychology.wichita.edu/surl/usabilitynews/81/pdf/ Usability\%20News\%2081\%20-\%20Shaikh2.pdf (accessed October 25, 2013).

Soper, D.S. and Mitra, S. (2013) An inquiry into mental models of web interface design. http://aisel.aisnet.org/amcis2013/ HumanComputerInteraction/GeneralPresentations/1/ (accessed June 10, 2013).

StatCounter. (2013) Top 10 desktop screen resolutions from Jan to Dec 2013. http://gs.statcounter.com/\#desktop-resolution-wwmonthly-201301-201312 (accessed December 18, 2013). 
Statista. (2013) Search and social are the most commonly used websites. http://www.statista.com/chart/1709/most-used-websitecategories/(accessed March 21, 2015).

Suresh, K. and Gopalakrishnan, S. (2012) Content organization in websites of agricultural universities in India: a web analytic study. http://digitalcommons.unl.edu/libphilprac/817/ (accessed June 10, 2015).

Tess, P.A. (2013) The role of social media in higher education classes (real and virtual) - a literature review. Comput. Human. Behav., 29, A60-A68. http://doi.org/10.1016/j.chb.2012.12.032.

Thatcher, A. (2008) Web search strategies: the influence of web experience and task type. Inf. Process. Manage., 44, 1308-1329. http://doi.org/10.1016/j.ipm.2007.09.004.

Trends in web technology. (2015) http://httparchive.org/trends.php (accessed April 01, 2015).

Vasantha, R.N. and Harinarayana, N.S. (2011) Identifying the location of web objects: a study of library websites. 8th International Caliber, 28-39.
Venables, W.N. and Ripley, B.D. (2002) Modern Applied Statistics With S. Springer Science \& Business Media.

Volkamer, M. and Renaud, K. (2013) Mental Models - General Introduction and Review of Their Application to Human-Centred Security. In Fischlin M. and Katzenbeisser, S. (eds), Number Theory and Cryptography, pp. 255-280. Springer, Berlin Heidelberg.

Weinberg, J.D., Freese, J. and McElhattan, D. (2014) Comparing data characteristics and results of an online factorial survey between a population-based and a crowdsource-recruited sample. Sociol. Sci., 1, 292-310.

Wickham, H. (2009) ggplot2. Springer New York, New York, NY. http://link.springer.com/10.1007/978-0-387-98141-3 (accessed May 28, 2015).

Xiang, Z., Wang, D., O'Leary, J.T. and Fesenmaier, D.R. (2014) Adapting to the Internet: trends in travelers' use of the web for trip planning. J. Travel Res., http://doi.org/10.1177/ 0047287514522883 .

\section{APPENDIX}

Appendix 1. Elements with their descriptions used in the prestudy.

\begin{tabular}{|c|c|}
\hline Name of the element & Description \\
\hline About us & Here you will find information about the company. \\
\hline About us & Here you will find information about the web portal. \\
\hline About us & Here you will find information about the online newspaper. \\
\hline Accessibility & $\begin{array}{l}\text { Here you will find information regarding the measures taken to make the website accessible to } \\
\text { persons with special needs (e.g. color blindness). }\end{array}$ \\
\hline Advertising area & Here you will find a presentation area for ads, banners of products or services. \\
\hline Advertising area (for external products) & Here you will find a presentation area for ads, banners of external companies. \\
\hline Advertising area (for internal products) & Here you will find a presentation area for ads, banners of products of the website. \\
\hline Archive & Here you will find the website archive, with stored articles and reports. \\
\hline Contact & $\begin{array}{l}\text { Here you will find contact details to get in touch with the company/operator of the website } \\
\text { (postal/E-mail-address, telephone number, etc.) }\end{array}$ \\
\hline Cookies \& Internet Advertising & Here you will find information about the use of cookies and/or personalized ads. \\
\hline Copyright & Here you will find information about copyright topics. \\
\hline Corporate Responsibility & Here you will find information about corporate responsibility and regulations. \\
\hline Country Selection & Here you can select the country website. \\
\hline Direct order & Here you can order a product directly with a provided link or by entering the order number. \\
\hline Disclaimer & $\begin{array}{l}\text { Here you will find a statement intended to specify or delimit the scope of rights and obligations } \\
\text { that may be exercised and enforced by parties in a legally recognized relationship. }\end{array}$ \\
\hline E-Paper Version & Here you will find an electronic version of the newspaper. \\
\hline
\end{tabular}


Appendix 1. Continued.

\begin{tabular}{|c|c|}
\hline Name of the element & Description \\
\hline & $\begin{array}{l}\text { Here you will find information about ethics policy (e.g. code of behavior, guidelines regarding } \\
\text { ethics) of the website. }\end{array}$ \\
\hline Feedback & Here you will find a link or an option to send a message to the operator of the website. \\
\hline Frequently Asked Questions (FAQ) & Here you will find answers to frequently asked questions. \\
\hline Help & Here you will find support if you need help or information. \\
\hline Home & Link to the Homepage. \\
\hline Hotline & Here you will find the number of the website's hotline/call center. \\
\hline Job & Here you will find job offers of the online shop. \\
\hline Jobs & Here you will find job offers of the company. \\
\hline Legal information & $\begin{array}{l}\text { Here you will find legal information concerning the website such as general terms and } \\
\text { conditions of use, disclaimer, legal notice, etc. }\end{array}$ \\
\hline Legal notice & Here you will find information about the owner of the website. \\
\hline Login & Here you can register with or log into the website of the company. \\
\hline Login & Here you can register with or log into the web portal. \\
\hline Login & Here you can register with or log into the online newspaper. \\
\hline Login & Here you can register with or log into the online shop. \\
\hline Logo & Here you will find the company logo/name. \\
\hline Logo & Here you will find the web portal logo/name. \\
\hline Logo & Here you will find the online newspaper logo/name. \\
\hline Logo & Here you will find the online shop logo/name. \\
\hline Online Community & $\begin{array}{l}\text { Here you will find an online community to share experiences about products, services and the } \\
\text { website. This could be a forum, a blog or similar application. }\end{array}$ \\
\hline Partner companies & Here you will find information about partner companies/websites. \\
\hline Payment methods & Here you will find a list of payment methods that can be used to buy products or services. \\
\hline Policies & Here you will find information about the website's policies (e.g. code of behavior, guidelines). \\
\hline Press releases & Here you will find website's press releases. \\
\hline Privacy notice & Here you will find the website's privacy policy statement. \\
\hline Recommendations & Here you will find daily deals, most popular products and current offers. \\
\hline Rich Footer & $\begin{array}{l}\text { Here you will find a list of links to main areas and important topics of the website, organized in } \\
\text { multiple columns. }\end{array}$ \\
\hline RSS Feed & $\begin{array}{l}\text { Here you can receive updated information (news, products, services, offers) via RSS feed on a } \\
\text { regular basis. }\end{array}$ \\
\hline Search Field & Here you can search the website. \\
\hline Security & $\begin{array}{l}\text { Here you will find information about the security of the system of the website as well as the } \\
\text { protection of data privacy. }\end{array}$ \\
\hline Select country/language & Here you can select your country of origin/language settings for the website. \\
\hline
\end{tabular}


Appendix 1. Continued.

\begin{tabular}{ll} 
Name of the element & Description \\
Set as Homepage & Here you will find an option to set the website as Home Page of your browser. \\
Shipping Costs & Here you will find an overview of the shipping costs for different products. \\
Shopping cart & Here you will find an overview of the products you have chosen for purchase. \\
Sitemap & Here you will find a hierarchical presentation of all sub-categories of the website. \\
Social Networks & Here you can share and/or like elements of the website via different social networks. \\
Sub Navigation & Here you will find further links to subpages of the website. This is an additional navigational \\
& area in addition to the main navigation area. \\
Subarea & Here you will find further products, information, services, etc. of the website. \\
Subscription & Here you will find an option to subscribe to a newspaper (online and offline). \\
Sustainability & Here you will find information about the sustainability measures and policy of the website. \\
To the top & Here you can scroll with one click easily to the top of the website. \\
Wishlist & Here you can list products you want to own or to buy. \\
\hline
\end{tabular}

